\title{
Pre-radiation Chemotherapy for Malignant Glioma in Adults
}

\author{
Sarah Kirby, David Macdonald, Barbara Fisher, Laurie Gaspar \\ and Gregory Cairncross
}

\begin{abstract}
Purpose: To review our experience with pre-radiation chemotherapy for malignant glioma. Methods: Consecutive adults with newly diagnosed glioblastoma, anaplastic astrocytoma, anaplastic oligodendroglioma and anaplastic mixed glioma with a Karnofsky Performance Score of 60 or greater were treated with one cycle of procarbazine, lomustine and vincristine or lomustine alone, prior to radiation. Computed tomographic scans were obtained soon after surgery, eight weeks later, after radiation, and at regular intervals thereafter. The effects of chemotherapy and subsequent radiation and durations of tumor control and survival were assessed in this single arm, single center, prospective trial. Results: Thirty-seven patients started chemotherapy, 36 were rescanned eight weeks after diagnosis. Five patients (16\%) responded to the first cycle of chemotherapy, three had glioblastoma and two anaplastic oligodendroglioma. Seven (19\%) progressed during the first cycle, 6 had glioblastoma; with the addition of radiation one progressive case responded, three stabilized, and three continued to progress. Median times to progression and median durations of survival were 26 weeks and 60 weeks for the entire group, 24 weeks and 44 weeks for glioblastoma, and greater than 104 weeks for anaplastic astrocytoma. Conclusions: Most patients with glioblastoma do not respond to one cycle of nitrosourea-based chemotherapy given prior to radiation, but patients with anaplastic oligodendroglioma sometimes do. Patients with anaplastic astrocytoma may not respond to one cycle of chemotherapy, but often respond to subsequent radiation. Judging by survival results, radiation can be delayed eight weeks without appearing to compromise patient outcome. Implications: Pre-radiation chemotherapy with newer agents can be evaluated more fully in the future knowing that brief delays in radiation are unlikely to yield substantially inferior results.
\end{abstract}

RÉSUMÉ: Chimiothérapie suivie de radiothérapie dans les gliomes malins chez l'adulte. But: Revoir notre expérience avec la chimiothérapie préirradiation dans les gliomes malins. Méthodes: Des adultes se présentant consécutivement avec un nouveau diagnostic de glioblastome, d'astrocytome anaplasique, d'oligodendrogliome anaplasique et de gliome mixte anaplasique, avec un score de fonctionnement à l'échelle de Karnofsky de 60 ou plus, ont êté traités avec un cycle de procarbazine, CCNU (lomustine) et vincristine [PCV], ou CCNU seul, avant la radiothérapie. Un CT scan a été fait tôt après la chirurgie, huit semaines plus tard, après la radiothérapie, et à intervalles réguliers par la suite. Les effets de la chimiothérapie et de la radiothérapie subséquente, et la durée de contrôle de la tumeur et de la survie ont été évalués dans cette étude prospective d'un groupe unique, dans un seul centre. Résultats: Trente-sept patients ont commencé la chimiothérapie, 36 ont subi un deuxième scan huit semaines après le diagnostic. Cinq patients $(16 \%)$ ont répondu au premier cycle de chimiothérapie, dont trois qui présentaient un glioblastome et deux un oligodendrogliome anaplasique. Sept (19\%) avaient progressé pendant le premier cycle, dont six avaient un glioblastome. Avec la radiothérapie subséquente, un cas qui avait progressé a répondu, trois se sont stabilisés et trois ont continué à progresser. Les médianes pour la durée de la période stable et de la survie étaient de 26 et 60 semaines respectivement pour le groupe entier, de 24 et 44 semaines pour le glioblastome et de plus de 104 semaines pour l'astrocytome anaplasique. Conclusions: La plupart des patients porteurs d'un astrocytome ne répondent pas à un cycle de chimiothérapie administré avant l'irradiation, mais les patients atteints d'oligodendrogliome anaplasique y répondent parfois. Il arrive que les patients qui ont un astrocytome anaplasique ne répondent pas a un cycle de chimiothérapie, mais ils répondent souvent à la radiothérapie ultérieurement. Si on en juge d'après la survie, l'irradiation peut être retardée de huit semaines sans que le résultat du traitement ne s'en trouve compromis. Implications: La chimiothérapie au moyen des nouveaux produits, administrée avant l'irradiation, pourra à l'avenir être mieux évaluée en sachant qu'un court délai dans l'administration de la radiothérapie n'est pas susceptible de donner de moins bons résultats.

Can. J. Neurol. Sci. 1996; 23: 123-127

Increasingly, oncologists are prescribing chemotherapy prior to radiation for brain cancers of children and adults. For infants and young children, effective chemotherapy allows radiation, which is toxic to the developing brain, to be delayed until the nervous system matures more fully. ${ }^{1}$ For older children, effective chemotherapy, if it is to be administered in optimal doses, may require greater bone marrow reserve than customarily remains following whole neuraxis radiation, the single best treatment for many pediatric brain tumor patients. ${ }^{2}$ For adults, the rationale for pre-radiation chemotherapy is less clearly defined but indications are gradually emerging as active drugs and regimens are identified ${ }^{3}$ For

From the Department of Neurology (S.K.), Dalhousie University, Halifax: Departments of Clinical Neurological Sciences and Oncology (D.M.,B.F.,G.C.), University of Westem Ontario, and London Regional Cancer Centre, London, Ontario, and Department of Radiation Oncology (L.G.), Wayne State University, Detroit, Michigan. RECEIVED ALGUST 4, 1995. ACCEPTED IN FINAL FORM OCTOBER 11, 1995.

Reprint requests to: J. Gregory Cairncross. MD, London Regional Cancer Centre. 790 Commissioners Road, East, London, Ontario, Canada N6A 4L6 
example, patients with CNS lymphoma receive methotrexate neoadjuvantly because methotrexate is safe and effective given prior to radiation but neurotoxic afterwards. ${ }^{4}$ In this context we investigated the safety and efficacy of a single cycle of "standard" chemotherapy, usually procarbazine, CCNU (lomustine) and vincristine (PCV) prior to radiation for patients with newly diagnosed malignant glioma.

\section{MethodS}

Consecutive adult patients (age $\geq 18$ years) seen at the London Regional Cancer Centre (January 1992 - June 1993) with newly diagnosed malignant glioma, good neurologic function (Karnofsky Performance Score (KPS) $\geq 60$ ) and no contraindication to cytotoxic therapy, received chemotherapy prior to standard limited field full dose radiotherapy. [This treatment policy was adopted at our center at a time when there were delays in starting radiation treatment for many cancer patients. Glioma patients with poor performance status (KPS $<60$ ) were offered short course whole brain radiation (3000 cGy in 10 fractions over two weeks) on lower energy machines where treatment began within four weeks of diagnosis. The following experience with good KPS patients did not occur in the context of a formal trial.] All patients had a computed tomographic (CT) scan prior to the fifth postoperative day to image residual tumor and determine the extent of resection. ${ }^{5}$ Chemotherapy usually began within two weeks of surgery. Most patients were treated with the dose-intensified PCV regimen (IPCV) described in Cairncross et al., ${ }^{6}$ although several received standard dose $\mathrm{PCV},{ }^{7}$ or $\mathrm{CCNU}$ as a single agent $\left(130 \mathrm{mg} / \mathrm{m}^{2}\right.$ orally). When weekly blood counts or multiple visits to the Centre for vincristine injections were problematic, standard dose PCV or CCNU alone were prescribed in preference to intensive PCV. Patients were rescanned six weeks later (eight weeks after surgery) to assess response. Response to chemotherapy was based on a measurable change in tumor size using criteria advocated by Macdonald et al. ${ }^{8}$ [Partial response $-50 \%$ or greater decrease in maximum cross-sectional area, clinically stable or improved, steroid dose stable or decreased; progressive disease - $25 \%$ or greater increase in maximum cross-sectional area, clinically stable or worse, steroid dose stable or increased.] Subsequently patients with glioblastoma and anaplastic astrocytoma received local field irradiation by conventional external beam $(6000 \mathrm{cGy}$ in 30 fractions over six weeks) while continuing chemotherapy to a maximum of seven cycles or until the tumor progressed or toxicity precluded further treatment. Patients were scanned again after radiation (16-20 weeks after surgery) and then at three to four month intervals, or as clinically indicated. Provided the tumor remained under control and toxicity due to chemotherapy was acceptable, patients with anaplastic oligodendroglioma and anaplastic mixed glioma were treated with four cycles of chemotherapy, then irradiated. Corticosteroids were used in the lowest doses required to maintain neurologic function, tapered slowly, and not used as antiemetics. Anticonvulsants were prescribed as required. Dates of progression and death were recorded and median times to progression and death calculated. For this analysis, the date of progression was the date the tumor was first noted to have progressed even though stabilization may have occurred subsequently with the addition of radiation. Salvage therapies were individualized and included corticosteroids, re-operation, stereotactic radiosurgery, and investigational chemotherapy.

\section{RESULTS}

Clinical features and response to treatment by tumor type are summarized in Tables 1-3. Thirty-seven patients [ 23 male, 14 female, ages 31-75 (mean 55), KPS 60-100 (mean 75)] received pre-radiation chemotherapy. Thirty-two had measurable disease after surgery (26 partial resections, six biopsies), five had complete resections. Twenty-two patients had a glioblastoma, eight anaplastic astrocytoma, five anaplastic oligodendroglioma and two anaplastic mixed glioma. Twenty-seven were treated with IPCV, three modified I-PCV, two PCV and five CCNU alone. Effectiveness of chemotherapy was assessable in 36 , objective response in 31 ; one patient with a glioblastoma developed medical complications unrelated to chemotherapy, was not rescanned, and died seven weeks after surgery. Overall, five patients (16\%) had a partial response to the first cycle of chemotherapy; three had glioblastoma and two anaplastic oligodendroglioma. Only seven patients (19\%) progressed during the first cycle; with the addition of radiation one of them responded, three stabilized, and three continued to progress. For the entire group the median time to progression was 26 weeks and the median survival 60 weeks.

For glioblastoma ( $\mathrm{n}=21 ; 19$ assessable for response), three patients $(16 \%)$ had a partial response to the first cycle of chemotherapy (Figure), 10 had stable disease, six (29\%) progressed, and two with complete resections did not progress. With radiation one patient with progressive disease had a partial response, three stabilized, and two continued to progress; ten others were unchanged but one partial responder improved further, one with stable disease had a partial response, and three stable patients progressed. Median time to progression was 24 weeks and median survival was 44 weeks. For anaplastic astrocytoma $(n=8 ; 6$ assessable for response), no patient responded to the first cycle, five remained stable, one progressed, and two with complete resections did not progress. With radiation the progressive case continued to progress, four were unchanged, and three stable patients with measurable disease (50\%) responded. Median time to progression and median survial have not been reached (median follow-up 110 weeks). For anaplastic oligodendroglioma and mixed glioma $(n=7)$, two patients had partial responses to the first cycle, four stable disease, and one with a complete resection did not progress (this patient was irradiated after one cycle). With subsequent chemotherapy both partial responders improved further (one achieved a complete response, the other had a major partial response but was beginning to progress at the end of the fourth cycle), and one stable patient had a partial response. Two stable patients developed hepatotoxicity due to chemotherapy and were irradiated prematurely (i.e., after one and two cycles, respectively) and one remained stable through four cycles. Median time to progression was 31 weeks and median survival will be at least 90 weeks.

Nausea, anorexia, occasional vomiting, fatigue and myelosuppression were observed to varying degrees during pre-radiation chemotherapy. There were no instances of neutropenic sepsis, excessive bruising or bleeding, or toxic death, but one patient with hepatotoxicity became profoundly jaundiced and was hospitalized. 
Table 1: Glioblastoma Multiforme $(n=22)$

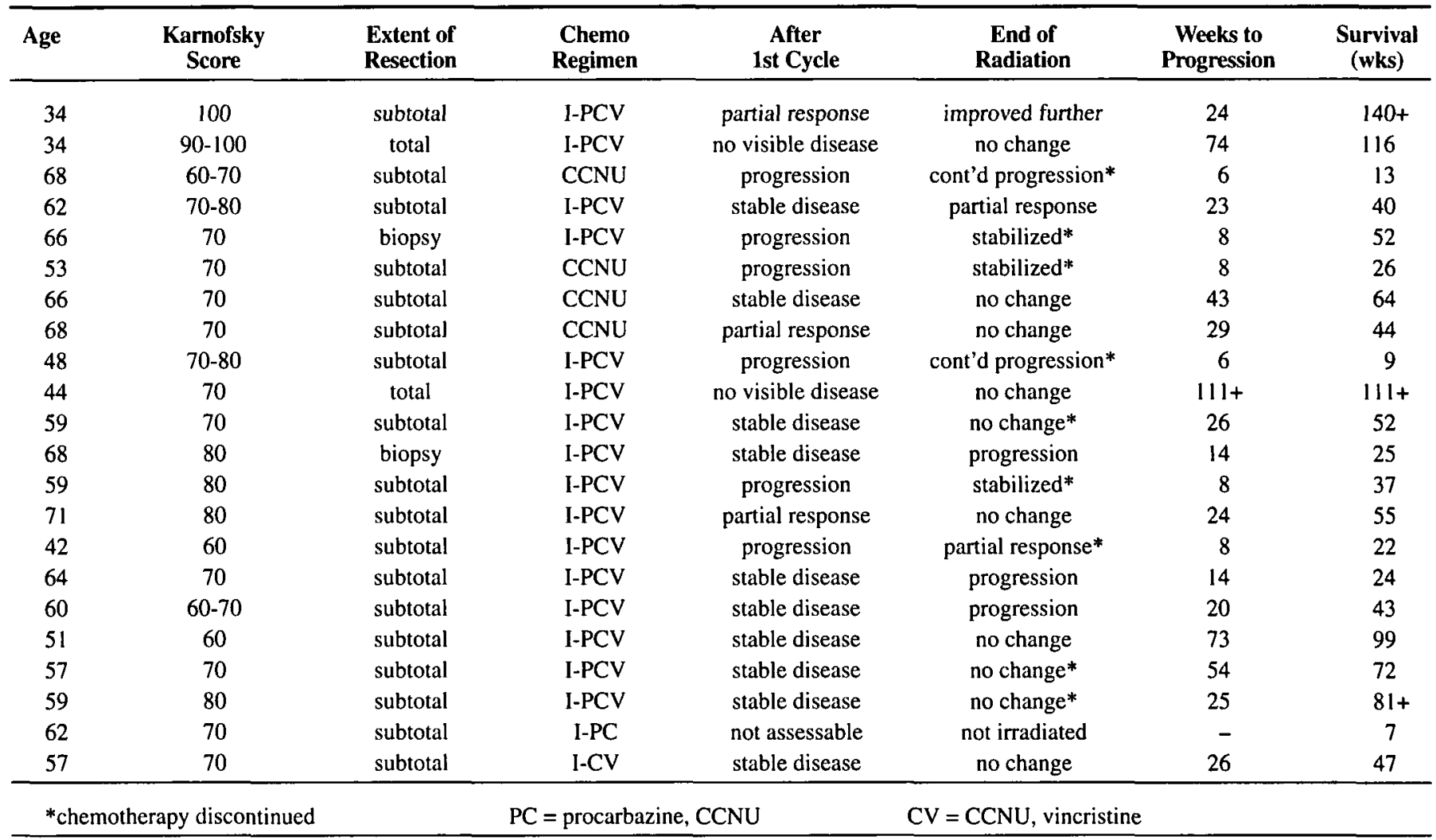

Table 2: Anaplastic Astrocytoma $(\mathrm{n}=8)$

\begin{tabular}{|c|c|c|c|c|c|c|c|}
\hline Age & $\begin{array}{c}\text { Karnofsky } \\
\text { Score }\end{array}$ & $\begin{array}{l}\text { Extent of } \\
\text { Resection }\end{array}$ & $\begin{array}{l}\text { Chemo } \\
\text { Regimen }\end{array}$ & $\begin{array}{c}\text { After } \\
\text { 1st Cycle }\end{array}$ & $\begin{array}{l}\text { End of } \\
\text { Radiation }\end{array}$ & $\begin{array}{l}\text { Weeks to } \\
\text { Progression }\end{array}$ & $\begin{array}{c}\text { Survival } \\
\text { (wks) }\end{array}$ \\
\hline 73 & 60 & biopsy & $\mathrm{CCNU}$ & progression & cont'd progression* & 5 & 15 \\
\hline 56 & $60-70$ & biopsy & I-PCV & stable disease & partial response & $122+$ & $122+$ \\
\hline 31 & 70 & subtotal & I-PCV & stable disease & partial response & $110+$ & $110+$ \\
\hline 41 & 90 & subtotal & I-PCV & stable disease & no change & 23 & $120+$ \\
\hline 31 & 90 & total & I-PCV & no visible disease & no change & $106+$ & $106+$ \\
\hline 70 & 80 & biopsy & I-PCV & stable disease & no change & 104 & $120+$ \\
\hline
\end{tabular}

*chemotherapy discontinued

Table 3: Anaplastic Oligodendroglioma and Mixed Glioma $(n=7)$

\begin{tabular}{|c|c|c|c|c|c|c|c|c|c|}
\hline Age & $\begin{array}{c}\text { Karnofsky } \\
\text { Score }\end{array}$ & $\begin{array}{l}\text { Extent of } \\
\text { Resection }\end{array}$ & $\begin{array}{c}\text { Chemo } \\
\text { Regimen }\end{array}$ & $\begin{array}{l}\text { Cycles } \\
\text { Pre-RT }\end{array}$ & $\begin{array}{c}\text { After } \\
\text { 1st Cycle }\end{array}$ & $\begin{array}{l}\text { End of } \\
\text { Chemo }\end{array}$ & $\begin{array}{c}\text { End of } \\
\text { Radiation }\end{array}$ & $\begin{array}{c}\text { Weeks to } \\
\text { Progression }\end{array}$ & $\begin{array}{c}\text { Survival } \\
\text { (wks) }\end{array}$ \\
\hline 36 & 80 & subtotal & $1-\mathrm{PCV}$ & 4 & partial response & progression & partial response & 31 & 86 \\
\hline 44 & 90 & subtotal & $\mathrm{I}-\mathrm{PCV}$ & 4 & partial response & complete response & no change & $122+$ & $122+$ \\
\hline 58 & 70 & subtotal & I-PCV & 1 & stable disease & - & no change & 22 & 44 \\
\hline 75 & 90 & subtotal & I-PC & 2 & stable disease & no change & no change & 22 & 39 \\
\hline
\end{tabular}




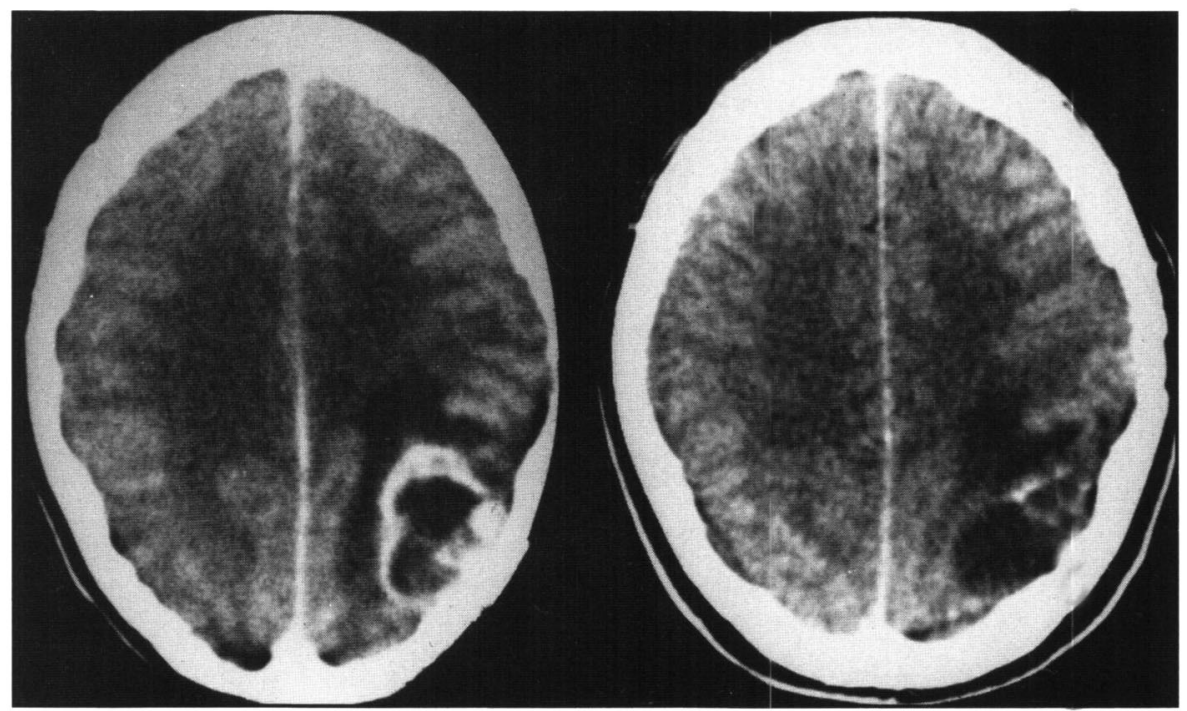

Figure: Contrast enhanced CT scans three days after partial resection of a left occipital glioblastoma (on the left) and eight weeks later (on the right) demonstrating a partial response to I-PCV chemotherapy given prior to radiation.

\section{Discussion}

A randomized controlled trial conducted twenty years ago by the Brain Tumor Study Group demonstrated that radiation to the whole brain in a dose of 5,000-6,000 cGy (170-200 cGy fractions over 5-7 weeks) and started within six weeks of diagnosis, when compared to supportive care, prolonged survival for patients with malignant glioma. ${ }^{9}$ Partial brain irradiation, as currently prescribed, is thought to confer a similar survival benefit with less risk of intellectual decline in longterm survivors. ${ }^{10} \mathrm{We}$ took advantage of a radiation delivery problem at a Canadian cancer center and evaluated the effects of standard chemotherapy given prior to radiation seeking to answer the following questions: do malignant gliomas respond to pre-radiation chemotherapy and can radiation, an unequivocally effective therapy for malignant glioma, be safely delayed while other treatments are evaluated first? Based on 37 consecutive patients with relatively good postoperative function, we conclude that radiation can be delayed at least eight weeks without compromising patient outcome while a single cycle of nitrosourea-based chemotherapy is administered and response assessed. The median times to progression and median durations of survival for the entire group ( 26 weeks, 60 weeks), glioblastoma only ( 24 weeks, 44 weeks), and anaplastic astrocytoma (> 104 weeks) were similar to those of comparably selected groups of patients from this center" ${ }^{\prime \prime}$ and elsewhere, but response rates were low.

Delaying radiation may not have adversely affected the outcome of this group of patients with malignant glioma but did this treatment approach compromise individual patients? This is a more difficult question to answer. Seven patients (19\%) progressed early on, but four of them were "salvaged" by subsequent radiation. Those who continued to progress despite radiation (8\%) lived nine, 13 and 15 weeks from diagnosis; it is questionable whether immediate radiation would have lengthened their lives substantially. It is well known that some patients with malignant glioma progress despite treatment; Gaspar et al. ${ }^{12}$ gave immediate postoperative radiotherapy to patients with malignant glioma ( $68 \%$ glioblastoma), performed end of treatment CT scans, and observed that $6 \%$ progressed during radiation. If radiation can be delayed eight weeks, can it be delayed longer? Once again the seven progressive cases are instructive, six had glioblastoma and the patient with an anaplastic astrocytoma was elderly, diagnosed by stereotactic biopsy, and probably had a glioblastoma. Under-diagnosis is a well recognized complication of biopsy procedures. ${ }^{13}$ Patients with glioblastoma may or may not tolerate longer delays in radiation, but it would appear from these data that delays in excess of eight weeks are safe for patients with anaplastic astrocytoma, anaplastic oligodendroglioma and anaplastic mixed glioma.

What can be said from this study about the efficacy of preradiation chemotherapy for malignant glioma? We draw three conclusions: first, some anaplastic oligodendrogliomas are sufficiently chemosensitive that response is evident after the first cycle of PCV; second, most patients with glioblastoma and anaplastic astrocytoma do not respond to one cycle of PCV; and third, provided corticosteroids are not tapered precipitously thereby causing "false" worsening, early tumor progression is readily apparent. More patients with glioblastoma and anaplastic astrocytoma might have responded had we delayed radiation another eight weeks and given a second cycle of PCV (traditionally response to chemotherapy is assessed after two cycles), but undoubtedly more would have progressed. Watne et al. ${ }^{14}$ delayed radiation and treated 19 patients with glioblastoma with two cycles of PCV, $48 \%$ progressed within 16 weeks of diagnosis. Due to delayed myelosuppression and long cycle times it may take 12-18 weeks to deliver two cycles of PCV chemotherapy. This lengthy interval is an obstacle to neoadjuvant chemotherapy with nitrosourea-based regimens but should not deter future studies of pre-radiation chemotherapy with cytotoxic drugs that can be given every three to four weeks.

Three additional comments are warranted. First, three patients with glioblastoma responded, but responders did not have longer survival or longer durations of tumor control than non-responders. Three responded, but were the responses genuine? Accurate response evaluation following subtotal tumor 
resection can be difficult in some patients, a point emphasized by Dropcho et al. ${ }^{15}$ Although it is conceivable that spontaneous resolution of surgical changes could have led to scan improvements eight weeks later, mis-interpreted as "responses" to chemotherapy, we minimized this possibility by obtaining early postoperative CT scans on all patients to assess residual tumor. ${ }^{5}$ False-positive responses were unlikely to have occurred in patients with anaplastic oligodendroglioma and mixed glioma because we delayed chemotherapy until surgical changes subsided and re-imaged them prior to treatment. Second, our experience with pre-radiation chemotherapy for malignant glioma is remarkably similar to that of other groups. Recht et al. ${ }^{16}$ treated 27 patients (80\% glioblastoma) with two cycles of intracarotid cisplatin and one cycle of intravenous BCNU, $13 \%$ responded. Dropcho et al..$^{15}$ treated 22 patients (60\% glioblastoma) with two cycles of intracarotid cisplatin, $14 \%$ responded and $27 \%$ progressed within ten weeks. Their definitions of response were similar to our own. Third, patients with glioblastoma seldom responded to radiation but patients with anaplastic astrocytoma, oligodendroglioma, or mixed glioma often did. Gaspar et al. ${ }^{12}$ made a similar observation with respect to the relative radiosensitivities of glioblastoma and intermediate grade gliomas.

Cytotoxic drugs may be more effective given prior to radiation, than after it, ${ }^{17}$ but there are other reasons to pursue preradiation chemotherapy for malignant glioma; if chemotherapy is administered neoadjuvantly response can be assessed independent of the effects of radiation. For both standard and investigational chemotherapy, an early assessment of efficacy is beneficial: continuing effective treatment is desirable for obvious reasons (e.g., smaller radiation volumes, better tumor control, longer survival), but stopping ineffective treatment also has important advantages, less toxicity and lower cost, to name but two. Moreover, we think pre-radiation evaluation of investigational drugs in newly diagnosed patients may be an important intermediate step in their assessment, particularly in view of neuro-oncology's "track record" of largely negative phase III studies. Perhaps randomized trials of chemotherapy for malignant glioma should be postponed until agents that appear promising in phase II studies of recurrent disease also prove to be effective when given prior to radiation. "Effective" in this context would mean at least as effective as neoadjuvant PCV. Several of the cooperative oncology groups are planning studies of pre-radiation chemotherapy for malignant glioma; these trials may be easier to interpret with our data in hand.

\section{ACKNOWLEDGEMENTS}

The authors thank Rose Allaster, Gwen Abdallah, Jill Ross, Bobbi Smuck and Alan Gavin for their invaluable assistance and support, and Pat Gray for preparing the manuscript.

\section{REFERENCES}

1. Duffner PK, Horowitz ME, Krischer JP, et al. Postoperative chemotherapy and delayed radiation in children less than three years of age with malignant brain tumors. N Engl J Med 1993; 328: 1725-1731.

2. Pollack IF. Brain tumors in children. N Engl J Med 1994; 331: 1500-1507.

3. Macdonald DR, Gaspar LE, Cairncross JG. Successful chemotherapy for newly diagnosed aggressive oligodendroglioma. Ann Neurol 1990; 27: 573-574.

4. DeAngelis LM, Yahalom J, Thaler HT, Kher U. Combined modality therapy for primary CNS lymphoma. J Clin Oncol 1992; 10: 635-641.

5. Cairncross JG, Pexman JHW, Rathbone MP, Del Maestro RF. Postoperative contrast enhancement in brain tumor patients. Ann Neurol 1985; 17: 570-572.

6. Cairncross JG, Macdonald DR, Ludwin S, et al. Chemotherapy for anaplastic oligodendroglioma. J Clin Oncol 1994; 12: 20132021.

7. Levin VA, Edwards MS, Wright DC, et al. Modified procarbazine, CCNU and vincristine (PCV-3) combination chemotherapy in the treatment of malignant brain tumors. Cancer Treat Rep 1980; 64: 237-241.

8. Macdonald DR, Cascino TL, Schold SC, Cairncross JG. Response criteria for phase II studies of malignant glioma. J Clin Oncol 1990; 8: 1277-1280.

9. Walker MD, Alexander E, Hunt WE, et al. Evaluation of BCNU and/or radiotherapy in the treatment of anaplastic gliomas. J Neurosurg 1978; 49: 333-343.

10. Archibald YM, Lunn D, Ruttan LA, et al. Cognitive functioning in long-term survivors of high-grade glioma. J Neurosurg 1994; 80 : 247-253.

11. Winger MJ, Macdonald DR, Cairncross JG. Supratentorial anaplastic glioma in adults - prognostic importance of extent of resection and prior low grade glioma. J Neurosurg 1989; 71: 487-493.

12. Gaspar LE, Fisher BJ, Macdonald DR, et al. Malignant glioma timing of response to radiation therapy. Int J Radiat Oncol Biol Phys 1993; 25: 877-879.

13. Glantz MJ, Burger PC, Herndon JE, et al. Influence of the type of surgery on the histologic diagnosis in patients with anaplastic gliomas. Neurology 1991; 41: 1741-1744.

14. Watne K, Nome O, Hager B, Hirschberg H. Pre-radiation chemotherapy in glioma patients with poor prognosis factors. J NeuroOncol 1992; 13:261-264.

15. Dropcho EJ, Rosenfeld SS, Morawetz RB, et al. Preradiation intracarotid cisplatin treatment of newly diagnosed anaplastic gliomas. J Clin Oncol 1992; 10: 452-458.

16. Recht L, Fram RJ, Strauss G, et al. Preirradiation chemotherapy of supratentorial malignant primary brain tumors with intracarotid cis-Platinum (CDDP) and i.v. BCNU: A phase II trial. Am J Clin Oncol 1990; 13: 125-131.

17. Bellamy A, Hill B. Interactions between clinically effective antitumor drugs and radiation in experimental systems. Biochim Biophys Acta 1984; 738: 125-166. 